\title{
Decontamination of the Digestive Tract and Oropharynx in ICU Patients
}

\author{
A.M.G.A. de Smet, M.D., J.A.J.W. Kluytmans, M.D., Ph.D., B.S. Cooper, Ph.D., \\ E.M. Mascini, M.D., Ph.D., R.F.J. Benus, M.D., T.S. van der Werf, M.D., Ph.D., \\ J.G. van der Hoeven, M.D., Ph.D., P. Pickkers, M.D., Ph.D., D. Bogaers-Hofman, I.C.P., \\ N.J.M. van der Meer, M.D., Ph.D., A.T. Bernards, M.D., Ph.D., E.J. Kuijper, M.D., Ph.D., \\ J.C.A. Joore, M.D., M.A. Leverstein-van Hall, M.D., Ph.D., A.J.G.H. Bindels, M.D., Ph.D., \\ A.R. Jansz, M.D., R.M.J. Wesselink, M.D., Ph.D., B.M. de Jongh, M.D., Ph.D., \\ P.J.W. Dennesen, M.D., Ph.D., G.J. van Asselt, M.D., Ph.D., L.F. te Velde, M.D., \\ I.H.M.E. Frenay, M.D., Ph.D., K. Kaasjager, M.D., Ph.D., F.H. Bosch, M.D., Ph.D., \\ M. van Iterson, M.D., S.F.T. Thijsen, M.D., Ph.D., G.H. Kluge, M.D., Ph.D., \\ W. Pauw, M.D., J.W. de Vries, M.D., Ph.D., J.A. Kaan, M.D., J.P. Arends, M.D., \\ L.P.H.J. Aarts, M.D., Ph.D., P.D.J. Sturm, M.D., Ph.D., H.I.J. Harinck, M.D., Ph.D., \\ A. Voss, M.D., Ph.D., E.V. Uijtendaal, Pharm.D., H.E.M. Blok, M.Sc., \\ E.S. Thieme Groen, M.D., M.E. Pouw, M.D., C.J. Kalkman, M.D., Ph.D., \\ and M.J.M. Bonten, M.D., Ph.D.
}

The authors' affiliations are listed in the Appendix. Address reprint requests to Dr. de Smet at the Division of Perioperative and Emergency Care, University Medical Center Utrecht, Q04.2.313, P.O. Box $85500,3508 \mathrm{GA}$ Utrecht, the Netherlands, or at a.desmet@umcutrecht.nl.

N Engl J Med 2009;360:20-31. Copyright () 2009 Massachusetts Medical Society.

\section{ABSTRACT}

\section{BACKGROUND}

Selective digestive tract decontamination (SDD) and selective oropharyngeal decontamination (SOD) are infection-prevention measures used in the treatment of some patients in intensive care, but reported effects on patient outcome are conflicting.

\section{METHODS}

We evaluated the effectiveness of SDD and SOD in a crossover study using cluster randomization in 13 intensive care units (ICUs), all in the Netherlands. Patients with an expected duration of intubation of more than 48 hours or an expected ICU stay of more than 72 hours were eligible. In each ICU, three regimens (SDD, SOD, and standard care) were applied in random order over the course of 6 months. Mortality at day 28 was the primary end point. SDD consisted of 4 days of intravenous cefotaxime and topical application of tobramycin, colistin, and amphotericin B in the oropharynx and stomach. SOD consisted of oropharyngeal application only of the same antibiotics. Monthly point-prevalence studies were performed to analyze antibiotic resistance.

\section{RESULTS}

A total of 5939 patients were enrolled in the study, with 1990 assigned to standard care, 1904 to SOD, and 2045 to SDD; crude mortality in the groups at day 28 was $27.5 \%$, $26.6 \%$, and $26.9 \%$, respectively. In a random-effects logistic-regression model with age, sex, Acute Physiology and Chronic Health Evaluation (APACHE II) score, intubation status, and medical specialty used as covariates, odds ratios for death at day 28 in the SOD and SDD groups, as compared with the standard-care group, were 0.86 ( $95 \%$ confidence interval [CI], 0.74 to 0.99 ) and 0.83 ( $95 \%$ CI, 0.72 to 0.97 ), respectively.

CONCLUSIONS

In an ICU population in which the mortality rate associated with standard care was $27.5 \%$ at day 28 , the rate was reduced by an estimated 3.5 percentage points with SDD and by 2.9 percentage points with SOD. (Controlled Clinical Trials number, ISRCTN35176830.) 
NFECTIONS ACQUIRED IN THE INTENSIVE care unit (ICU) are important complications of the treatment of critically ill patients, increasing morbidity, mortality, and health care costs. ${ }^{1}$ Reductions in the incidence of respiratory tract infections have been achieved with the use of prophylactic antibiotic regimens, such as selective decontamination of the digestive tract $(\mathrm{SDD})^{2,3}$ and selective oropharyngeal decontamination (SOD). ${ }^{4,5}$

The SDD approach ${ }^{6,7}$ consists of prevention of secondary colonization with gram-negative bacteria, Staphylococcus aureus, and yeasts through application of nonabsorbable antimicrobial agents in the oropharynx and gastrointestinal tract, preemptive treatment of possible infections with commensal respiratory tract bacteria through systemic administration of cephalosporins during the patient's first 4 days in the ICU, and maintenance of anaerobic intestinal flora through selective use of antibiotics (administered both topically and systemically) without antianaerobic activity. ${ }^{7}$ Despite the beneficial effects of SDD on infection rates, most studies have lacked sufficient statistical power to detect effects on survival. In metaanalyses and in three single-center, randomized studies, the use of SDD, including a short course of systemic antibiotics, was associated with improved survival. ${ }^{2,3,8-10}$

SOD (application of topical antibiotics in the oropharynx only) has been postulated as an alternative to SDD for the prevention of ventilatorassociated pneumonia. ${ }^{4,5}$ Although several studies have identified the pivotal role of oropharyngeal colonization in the pathogenesis of ventilatorassociated pneumonia ${ }^{11,12}$ and the efficacy of SOD in preventing ventilator-associated pneumonia appears to be similar to the efficacy of SDD, ${ }^{13,14}$ a head-to-head comparison of the two strategies is needed. Because of methodologic issues, ${ }^{15,16}$ such as single-center study designs with limited generalizability, and concern about increased selection of antibiotic-resistant pathogens, ${ }^{17,18}$ the routine use of SDD and SOD has remained controversial and has not been recommended in international guidelines. ${ }^{19,20}$

\section{METHODS}

\section{STUDY DESIGN}

We performed a controlled, crossover study using cluster randomization in 13 ICUs between May
2004 and July 2006. The participating ICUs differed in size and teaching status, reflecting all levels of intensive care in the Netherlands. (More information on the ICUs can be found in the Supplementary Appendix, available with the full text of this article at NEJM.org.) Since the interventions included ecologic changes in the ICU, an individualized, randomized design would have allowed the treatment of a patient in one study group to influence the treatment of a patient in another group. Therefore, cluster randomization was used, and all three study regimens (SDD, SOD, and standard care) were administered to all eligible patients over the course of 6 months, with the order of regimens randomly assigned. A crossover design was used to control for unit-specific characteristics. Randomization was performed by a clinical pharmacist who was not involved in patient care in any of the participating units and who was unaware of the identity of each ICU. The order in which the regimens were assigned was randomly generated by computer software (Design, version 2.0, a Systat Module), with allocation to the wards in consecutive order of study start. Study periods were preceded by washout and wash-in periods (for more information see the Supplementary Appendix). The antibiotics used were purchased by the hospitals. All authors vouch for the completeness and accuracy of the data presented.

Patients admitted to the ICU with an expected duration of mechanical ventilation of more than 48 hours or an anticipated ICU stay of more than 72 hours were eligible. Eligibility was assessed by physicians responsible for patient care in each unit. Pregnant patients and patients with documented or presumed allergy to any component of the antimicrobial study regimens were excluded.

The study protocol was approved by the institutional review board at each participating hospital. After reviewing the protocol, the boards waived the requirement for informed consent. Permission to use patient-specific medical data for analysis was obtained from patients or their representatives.

Inclusion rates were determined for each ICU and each study period. Research nurses visited each center regularly (at least twice per study period) and evaluated up to 50 consecutively admitted patients per visit (starting from a randomly chosen date) for eligibility and study inclusion.

The SDD regimen, which consisted of 4 days 
of intravenous cefotaxime and topical application of tobramycin, colistin, and amphotericin B in the oropharynx and stomach, was identical to the regimen used by de Jonge et al. ${ }^{2}$ (for more information see the Supplementary Appendix). The use of antibiotics with antianaerobic activity, such as amoxicillin, penicillin, amoxicillin-clavulanic acid, and carbapenems, was discouraged during the SDD period. Surveillance cultures of endotracheal aspirates and oropharyngeal and rectal swabs were obtained on admission and twice weekly thereafter.

SOD consisted of oropharyngeal application of the same paste used for SDD, with surveillance cultures of endotracheal aspirates and oropharyngeal swabs obtained on admission and twice weekly thereafter; there were no restrictions on physicians' choices of systemic antibiotic therapy. During the period of standard care, no surveillance cultures were obtained from patients, and there were no restrictions on physicians' choices of systemic antibiotic therapy.

Antibiotic resistance was monitored with the use of point-prevalence studies on the third Tuesday of each month. On these days, rectal swabs and endotracheal aspirates or throat swabs for surveillance cultures were obtained from all ICU patients, whether or not they were included in the study. The prevalence of specific pathogenresistance combinations was determined. (Details on the processing of surveillance cultures during SDD and SOD and on the monthly point-prevalence studies are available in the Supplementary Appendix.)

Approaches to infection control (other than the regimens being studied) did not change during the period of the study in any of the ICUs. (Oropharyngeal care is described in the Supplementary Appendix.)

\section{STATISTICAL ANALYSIS}

The original analysis plan, which specified inhospital death as the primary end point, did not take into account analysis of cluster effects and failed to specify how to address imbalances in baseline characteristics between study groups. However, the study design did not preclude postrandomization selection bias. ${ }^{21}$ It was subsequently recognized that such an analysis plan failed to conform to the Consolidated Standards for the Reporting of Trials (CONSORT) guidelines for reporting cluster-randomization trials. ${ }^{22}$ Failure to account for cluster effects (e.g., with the use of a random-effects model) would have increased the chance of reporting spuriously significant findings, and in the event of selection bias, failure to adjust for baseline characteristics could have led to bias in either direction. ${ }^{21,23}$ When confronted with these problems, we consulted a panel of experts in the field of clinical epidemiology and data analysis with no prior involvement in the study and no knowledge of outcome data. The panel unanimously recommended a revised analysis plan that overcame these problems. This plan specified mortality at day 28 as the primary end point (because it was thought that knowledge of the intervention being applied at any given time could have influenced discharge policies, compromising the reliability of hospital discharge as an end point) and the use of a random-effects logistic-regression model to adjust for all available covariates (the score on the Acute Physiology and Chronic Health Evaluation [APACHE II], intubation status, medical specialty [classified as surgical or other], age, and sex).

This plan was adopted, with no further revisions, and day 28 mortality data were subsequently collected through hospital and government systems (these data had not been available when the analysis plan was formulated). In-hospital mortality, prevalence of antibiotic resistance, and duration of mechanical ventilation, ICU stay, and hospital stay for surviving patients were secondary end points. (Details on the power calculation and statistical analysis of secondary end points are available in the Supplementary Appendix.)

\section{RESULTS}

\section{CHARACTERISTICS OF THE PATIENTS}

From May 2004 through July 2006, a total of 5939 patients were enrolled in 13 participating centers: 1990 received standard care, 1904 received SOD, and 2045 received SDD. Permission for use of patient-specific medical data could not be obtained for 12 patients (11 in the SDD group and 1 in the standard-care group), who were excluded from all analyses except those for unadjusted mortality; 44 patients were discharged alive from the hospital but were lost to follow-up at day 28. Overall, 48 patients crossed over to a subsequent study period. The total number of patients included in 


\begin{tabular}{|c|c|c|c|c|c|c|}
\hline \multirow[t]{2}{*}{ Characteristic } & \multirow[t]{2}{*}{$\begin{array}{c}\text { SDD } \\
(N=2045)\end{array}$} & \multirow[t]{2}{*}{$\begin{array}{c}\text { SOD } \\
(N=1904)\end{array}$} & \multirow[t]{2}{*}{$\begin{array}{l}\text { Standard Care } \\
(N=1990)\end{array}$} & \multicolumn{3}{|c|}{ P Value } \\
\hline & & & & $\begin{array}{l}\text { SDD vs. } \\
\text { Standard Care }\end{array}$ & $\begin{array}{l}\text { SOD vs. } \\
\text { Standard Care }\end{array}$ & $\begin{array}{l}\text { SDD vs. } \\
\text { SOD }\end{array}$ \\
\hline Age $-y r \dagger$ & $62.4 \pm 15.9$ & $61.4 \pm 16.3$ & $61.4 \pm 16.2$ & 0.04 & 0.88 & 0.05 \\
\hline Male sex — no. (\%) & $1244(61.2)$ & $1213(63.7)$ & $1220(61.3)$ & 0.90 & 0.13 & 0.09 \\
\hline Mean APACHE II score & $19.6 \pm 7.8$ & $19.5 \pm 8.2$ & $18.6 \pm 7.9$ & 0.00 & 0.001 & 0.63 \\
\hline APACHE II score $\geq 20$ - no. (\%) & $969(47.4)$ & $897(47.1)$ & $837(42.1)$ & 0.001 & 0.002 & 0.87 \\
\hline Mechanical ventilation — no.(\%) & 1890 (92.9) & $1793(94.2)$ & $1753(88.1)$ & 0.00 & 0.00 & 0.12 \\
\hline \multicolumn{7}{|l|}{ Reason for admission — no. (\%) } \\
\hline Surgical & $923(45.4)$ & $866(45.5)$ & 973 (48.9) & 0.03 & 0.03 & 0.95 \\
\hline Medical & $1111(54.6)$ & $1038(54.5)$ & $1016(51.1)$ & & & \\
\hline \multicolumn{7}{|l|}{$\begin{array}{l}\text { Specialty of admitting physician - } \\
\text { no. (\%) }\end{array}$} \\
\hline Surgery & $605(29.7)$ & $551(28.9)$ & $609(30.6)$ & 0.56 & 0.26 & 0.60 \\
\hline Cardiothoracic surgery & $353(17.4)$ & $284(14.9)$ & $321(16.1)$ & 0.31 & 0.31 & 0.04 \\
\hline Neurosurgery & $105(5.2)$ & $140(7.4)$ & $145(7.3)$ & 0.006 & 0.95 & 0.005 \\
\hline Neurology & $124(6.1)$ & $144(7.6)$ & $128(6.4)$ & 0.70 & 0.19 & 0.08 \\
\hline Internal medicine & $382(18.8)$ & $371(19.5)$ & $393(19.8)$ & 0.45 & 0.84 & 0.60 \\
\hline Cardiology & $159(7.8)$ & $147(7.7)$ & $129(6.5)$ & 0.11 & 0.13 & 0.95 \\
\hline Pulmonology & $152(7.5)$ & $138(7.2)$ & $127(6.4)$ & 0.19 & 0.31 & 0.81 \\
\hline Other & $153(7.5)$ & $126(6.6)$ & $137(6.9)$ & 0.47 & 0.75 & 0.29 \\
\hline Unknown & $1(<1)$ & $3(0.2)$ & 0 & 1.00 & 0.12 & 0.36 \\
\hline \multicolumn{7}{|l|}{$\begin{array}{l}\text { Previous or preexisting condition - } \\
\text { no. (\%) }\end{array}$} \\
\hline Cardiovascular disease & $1031(50.7)$ & $899(47.2)$ & $976(49.1)$ & 0.31 & 0.25 & 0.03 \\
\hline Pulmonary disease & $530(26.1)$ & $448(23.5)$ & $489(24.6)$ & 0.29 & 0.45 & 0.07 \\
\hline Diabetes mellitus & $281(13.8)$ & $274(14.4)$ & $302(15.2)$ & 0.23 & 0.50 & 0.61 \\
\hline Chronic renal insufficiency & $155(7.6)$ & $135(7.1)$ & $119(6.0)$ & 0.05 & 0.17 & 0.54 \\
\hline Malignant solid tumor & $220(10.8)$ & $193(10.1)$ & $196(9.9)$ & 0.33 & 0.79 & 0.50 \\
\hline Metastasized cancer & $71(3.5)$ & $56(2.9)$ & $64(3.2)$ & 0.66 & 0.64 & 0.37 \\
\hline Hematologic cancer & $56(2.8)$ & $51(2.7)$ & $48(2.4)$ & 0.55 & 0.61 & 0.92 \\
\hline Immunodepression or AIDS & $60(2.9)$ & $47(2.5)$ & $47(2.4)$ & 0.28 & 0.84 & 0.38 \\
\hline Alcohol or drug abuse & $112(5.5)$ & $120(6.3)$ & $111(5.6)$ & 0.95 & 0.34 & 0.31 \\
\hline \multicolumn{7}{|c|}{$\begin{array}{l}\text { Place from which patient was admitted } \\
\text { to ICU - no. (\%) }\end{array}$} \\
\hline Emergency room & $509(25.0)$ & $475(24.9)$ & $465(23.4)$ & 0.23 & 0.26 & 0.97 \\
\hline Other ICU & $135(6.6)$ & $121(6.4)$ & $116(5.8)$ & 0.30 & 0.50 & 0.75 \\
\hline Hospital ward & $961(47.2)$ & $915(48.1)$ & $943(47.4)$ & 0.80 & 0.80 & 1.00 \\
\hline Other & $440(21.5)$ & $393(20.5)$ & $466(23.4)$ & 0.11 & 0.21 & 0.77 \\
\hline
\end{tabular}

* Plus-minus values are means \pm SD. Permission for use of patient-specific data could not be obtained for 11 patients in the selective digestive tract decontamination (SDD) group and 1 patient in the standard-care group. AIDS denotes acquired immunodeficiency syndrome, APACHE Acute Physiology and Chronic Health Evaluation, and SOD selective oropharyngeal decontamination.

$\dagger$ Values for age are based on age at the time of hospital admission.

The New England Journal of Medicine 


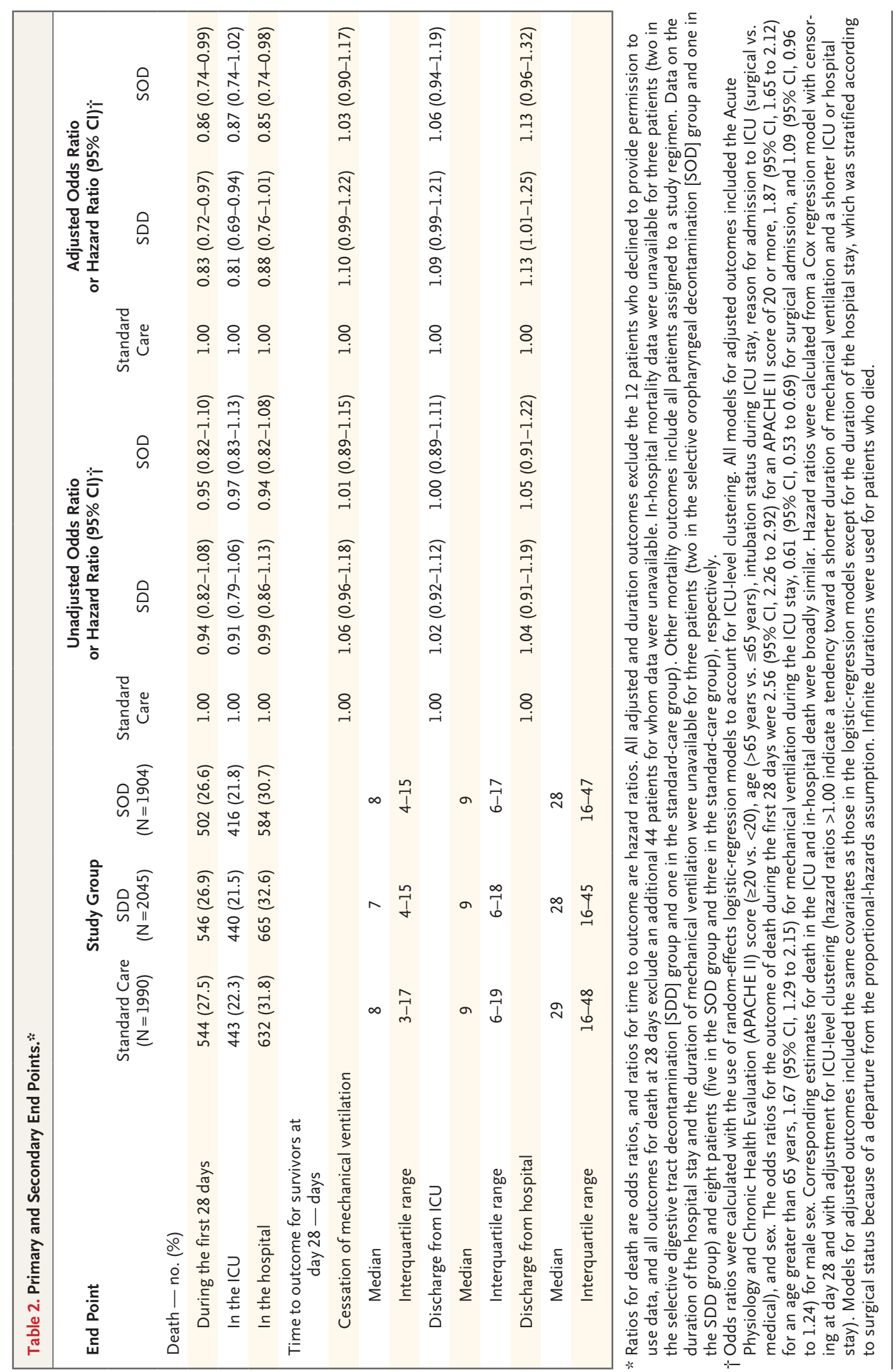


the study per center ranged from 119 in a 4-bed ICU in a nonteaching hospital to 1013 patients in a 43-bed ICU in a university hospital. (Details on patient enrollment per center are available in the Supplementary Appendix.)

Eligibility was determined for a total of 6565 ICU admissions (with 300 to 1518 patients screened for eligibility per center). The average proportion of ICU patients eligible for study inclusion per center was $29.5 \%$ and ranged from 16.3 to $51.8 \%$. Patients who were not eligible for the study had short ICU stays, in most cases after elective surgery. Of all eligible patients, $89.2 \%$ were included. Inclusion rates ranged from 51.8 to $100 \%$ per center. The mean inclusion rates for the SDD, SOD, and standard-care periods were $89.1 \%, 86.9 \%$, and $91.6 \%$, respectively $(\mathrm{P}=0.03$ for standard care vs. SOD, $\mathrm{P}>0.05$ for the other comparisons), and rates for the first, second, and third periods were $88.5 \%, 86.6 \%$, and $92.8 \%$, respectively $(\mathrm{P}=0.02$ for the first period vs. the third period, $\mathrm{P}>0.05$ for the other comparisons).

There were differences in baseline characteristics between patients in the standard-care group and those in the SOD and SDD groups (Table 1). Patients who received standard care had slightly lower APACHE II scores, were less likely to be receiving mechanical ventilation, and were more likely to have been admitted for surgical reasons. The proportions of patients who received antibiotics before admission to the ICU were similar in all three study groups. In the SOD and SDD groups, medication was administered according to protocol on $95.7 \%$ and $97.5 \%$ of all patientdays, respectively. Noncompliance, which was most frequent at the end of the ICU stay, was most often due to the patient's decision to decline medication.

\section{PRIMARY AND SECONDARY CLINICAL END POINTS}

Crude mortality at day 28 for patients in the standard-care, SOD, and SDD groups was $27.5 \%, 26.6 \%$, and $26.9 \%$, respectively. In a random-effects logistic-regression model adjusted for age, sex, APACHE II score, intubation status, medical specialty, study site, and study period, odds ratios for death during the first 28 days for the SOD and SDD groups, as compared with the standardcare group, were 0.86 (95\% confidence interval [CI], 0.74 to $0.99 ; \mathrm{P}=0.045)$ and 0.83 (95\% CI, 0.72 to $0.97 ; \mathrm{P}=0.02$ ), respectively (Table 2 ). When covariates were added to the model one at a time in order of statistical significance, it was evident that those with significant imbalances had the largest effect on the odds ratio (for more information see the Supplementary Appendix). The intracluster correlation coefficient was 0.010 . With a baseline rate of death during the first 28 days of $27.5 \%$, absolute and relative reductions in mortality at day 28 were $3.5 \%$ and $13 \%$, respectively, for the SDD group and $2.9 \%$ and $11 \%$, respectively, for the SOD group, corresponding with the needed-to-treat numbers of 29 and 34 to prevent one casualty at day 28 for SDD and SOD, respec-

\begin{tabular}{|c|c|c|c|c|c|c|}
\hline \multirow[t]{3}{*}{ Type of Infection } & \multicolumn{3}{|c|}{ Study Group } & \multicolumn{3}{|c|}{ Crude Odds Ratio $(95 \% \mathrm{CI})$} \\
\hline & $\begin{array}{l}\text { Standard Care } \\
\qquad(N=1990)\end{array}$ & $\begin{array}{c}\text { SOD } \\
(\mathrm{N}=1904)\end{array}$ & $\begin{array}{c}\text { SDD } \\
(N=2045)\end{array}$ & $\begin{array}{c}\text { SDD vs. Standard } \\
\text { Care }\end{array}$ & $\begin{array}{l}\text { SOD vs. Standard } \\
\text { Care }\end{array}$ & SDD vs. SOD \\
\hline & & no. (\%) & & & & \\
\hline Staphylococcus aureus & $22(1.1)$ & $9(0.5)$ & $9(0.4)$ & $0.40(0.18-0.86)$ & $0.43(0.20-0.93)$ & $0.93(0.37-2.40)$ \\
\hline Streptococcus pneumoniae & $3(0.2)$ & $1(0.1)$ & $1(0.0)$ & $0.32(0.03-3.12)$ & $0.35(0.04-3.35)$ & $0.93(0.06-14.90)$ \\
\hline GNF-GNR speciest' & $36(1.8)$ & $17(0.9)$ & $16(0.8)$ & $0.43(0.24-0.77)$ & $0.49(0.27-0.87)$ & $0.88(0.44-1.74)$ \\
\hline Enterobacteriaceae & $87(4.4)$ & $59(3.1)$ & $18(0.9)$ & $0.19(0.12-0.32)$ & $0.70(0.50-0.98)$ & $0.28(0.16-0.47)$ \\
\hline Enterococcus species & $55(2.8)$ & $49(2.6)$ & $48(2.3)$ & $0.85(0.57-1.25)$ & $0.93(0.63-1.37)$ & $0.91(0.61-1.36)$ \\
\hline Candida species & $16(0.8)$ & $14(0.7)$ & $8(0.4)$ & $0.49(0.21-1.11)$ & $0.91(0.45-1.85)$ & $0.53(0.23-1.24)$ \\
\hline $\begin{array}{l}\text { Patients with at least one episode } \\
\text { of bacteremia or candidemia - } \\
\text { no. (\%) }\end{array}$ & $186(9.3)$ & $124(6.5)$ & $88(4.3)$ & $0.44(0.34-0.57)$ & $0.68(0.53-0.86)$ & $0.65(0.49-0.85)$ \\
\hline
\end{tabular}

* SDD denotes selective digestive tract decontamination, and SOD selective oropharyngeal decontamination.

$\dagger$ Glucose-nonfermenting gram-negative rods (GNF-GNR) are characteristic of Pseudomonas aeruginosa, Stenotrophomonas maltophilia, and acinetobacter species. 
tively. There was a tendency for SDD and SOD to be associated with reductions in durations of mechanical ventilation, ICU stay, and hospital stay (Table 2). There was no evidence of an association of temporal trends, autocorrelation, or period-level effects with primary or secondary end points.

\section{MICROBIOLOGIC FINDINGS}

Among patients receiving SDD or SOD as compared with those receiving standard care, crude incidences of ICU-acquired bacteremia were significantly reduced for $S$. aureus, glucose-nonfermenting gram-negative rods (mainly Pseudomonas aeruginosa), and Enterobacteriaceae (Table 3). Patients receiving SDD had a lower incidence of ICU-acquired bacteremia with Enterobacteriaceae than did those receiving SOD. The incidence of ICU-acquired candidemia tended to be lower in the SDD group than in either the SOD group or the standard-care group, although the difference was not significant. No significant differences among the three study groups were observed for infection with Streptococcus pneumoniae or Enterococcus species. Clostridium difficile toxin was detected in 15 patients $(0.8 \%)$ in the standard-care group, 5 patients $(0.3 \%)$ in the SOD group, and 9 patients $(0.4 \%)$ in the SDD group.

The estimated completeness of surveillance cultures per center was, on average, $87 \%$ (range, 70 to 97 ) for respiratory tract samples and $87 \%$ (range, 62 to 100) for rectal samples. The rate of isolation of gram-negative bacteria from rectal swabs among patients receiving SDD was reduced from $56 \%$ at day 3 to $25 \%$ at day 8 and $15 \%$ at day 14 (Fig. 1). The rate of culture positivity for gram-negative bacteria in oropharyngeal swabs from patients receiving SDD ranged from $18 \%$ at day 2 to $4 \%$ at day 8 . Among patients treated with SOD, culture positivity ranged from $20 \%$ at day 2 to $7 \%$ at day 8 (Fig. 1).

In all, 2596 patients were included in the monthly point-prevalence surveillance studies for respiratory tract colonization (894 in the SDD group, 811 in the SOD group, and 891 in the standard-care group), and 2963 patients were included in the analysis of rectal colonization (988 in the SDD group, 947 in the SOD group, and 1028 in the standard-care group). Estimated completeness of culture surveillance per center was, on average, $87 \%$ (range, 67 to 98 ) for rectal samples and $82 \%$ (range, 69 to 95) for respiratory tract samples. The data from six point-prevalence measurements per study period were analyzed together. For all pathogen-antibiotic combinations, the rate of nonsusceptibility was less than $5 \%$ (Table 4 ). For multidrug resistance, the rate of nonsuscep-

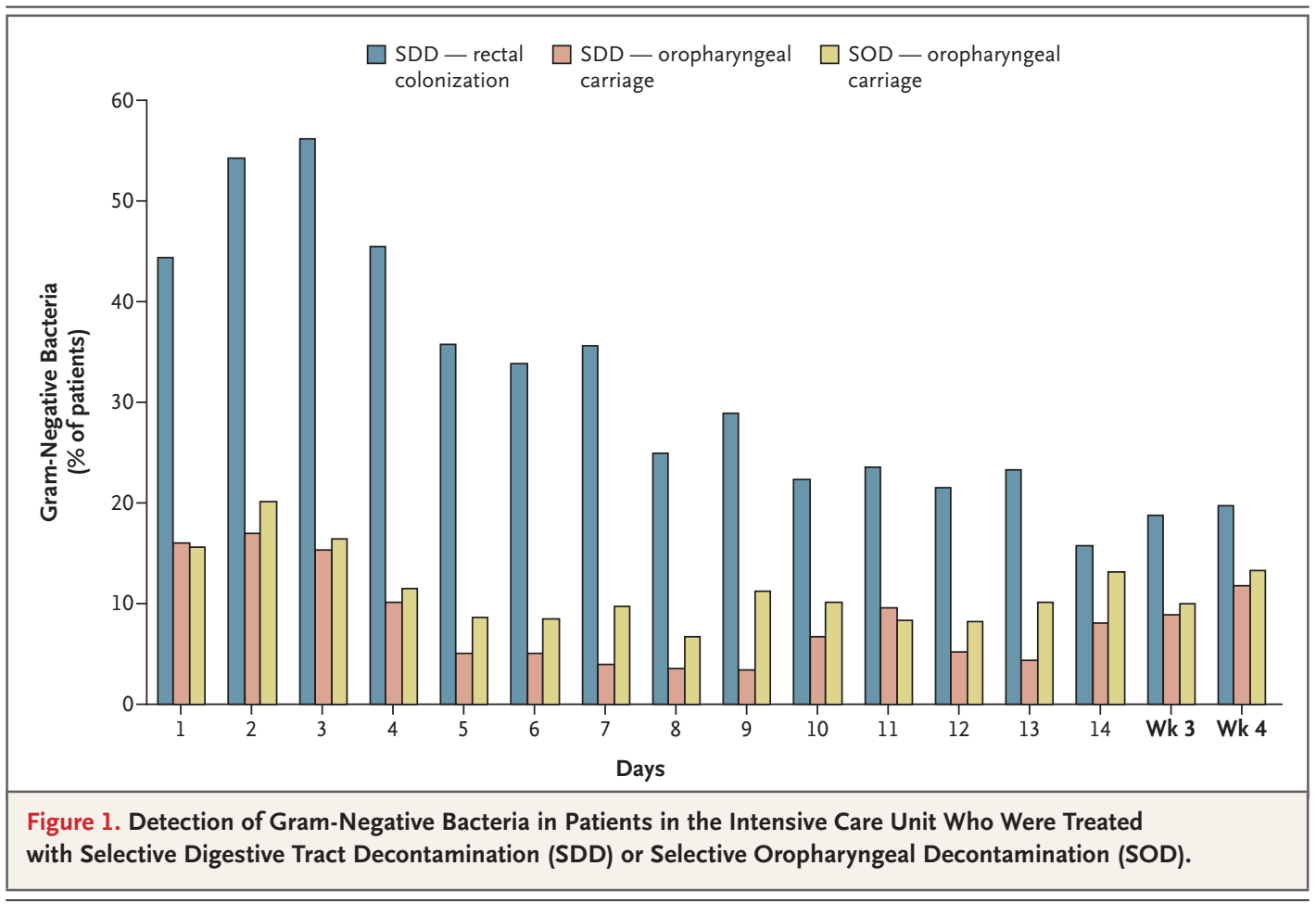




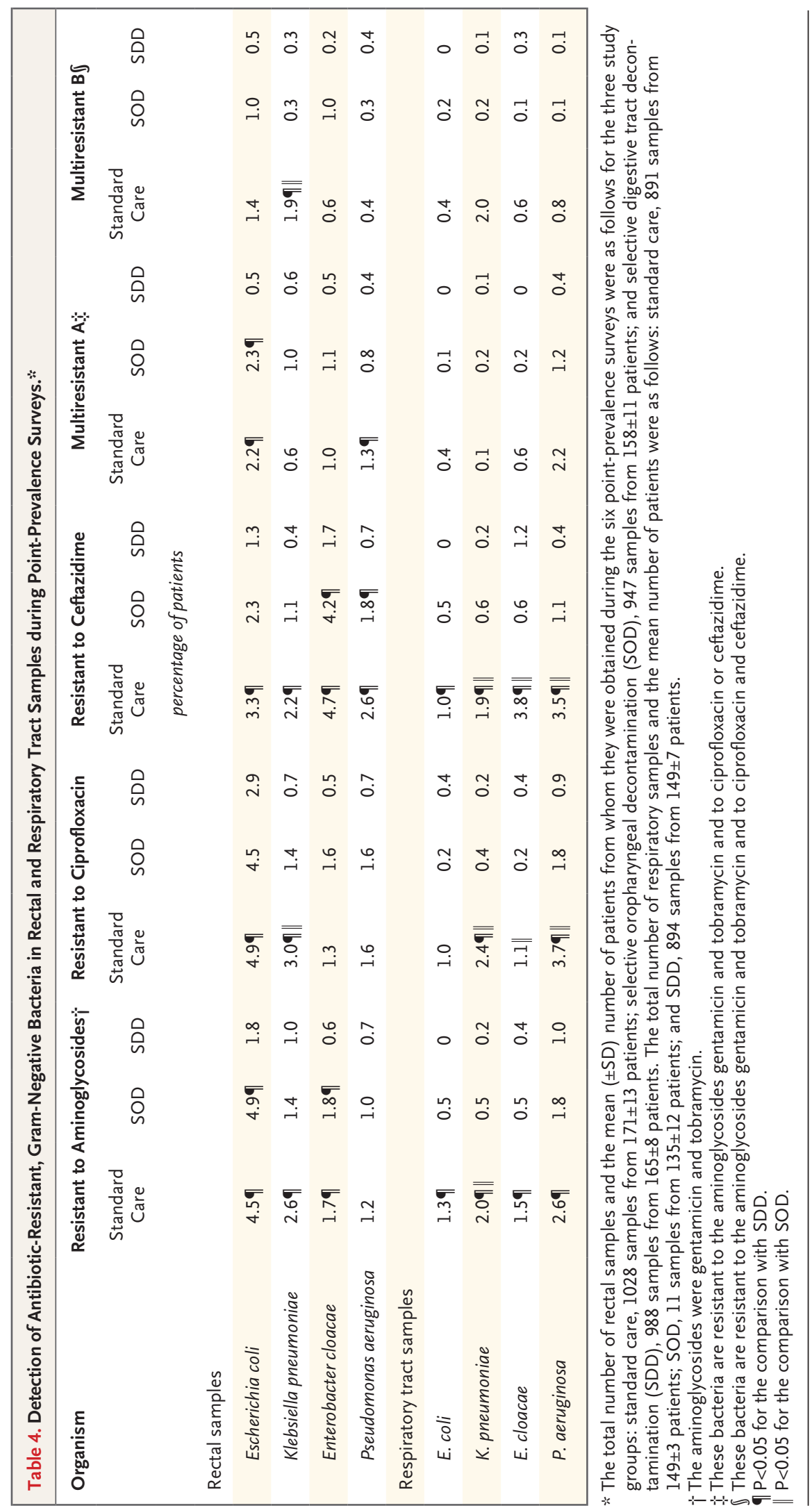

N ENGL J MED 360;1 NEJM.ORG JANUARY 1, 2009

The New England Journal of Medicine 
tibility was less than $2.5 \%$ for two antibiotics and less than or equal to $2 \%$ for three antibiotics. The proportion of patients with gram-negative bacteria in rectal swabs that were not susceptible to the marker antibiotics was lower with SDD than with standard care or SOD (Table 4). The proportions of patients with nonsusceptible bacteria in respiratory tract samples were similar in the SDD and SOD groups and were lower than the proportion in the standard-care group. There were no patients with methicillin-resistant $S$. aureus; eight patients had vancomycin-resistant enterococci in rectal swabs: six in the standard-care group $(0.6 \%)$ and two in the SOD group $(0.2 \%)$.

\section{ANTIBIOTIC USE}

The median number of defined daily doses of systemic antibiotic agents (including antifungal agents) per patient-day did not differ significantly among the SDD, SOD, and standard-care periods: 0.72 (interquartile range, 0.44 to 1.33), 0.84 (interquartile range, 0.25 to 1.58), and 0.84 (interquartile range, 0.29 to 1.55), respectively. During treatment with SDD as compared with standard care, the use of antimicrobial agents with antianaerobic activity was reduced by $27.8 \%$ for broad-spectrum penicillins, $45.7 \%$ for carbapenems, and $11.6 \%$ for lincosamides (Table 5). Furthermore, quinolone use (mainly ciprofloxacin) was reduced by $31.4 \%$. In contrast, systemic use of cephalosporins increased by $86.6 \%$. There were less pronounced differences in antibiotic use between the SOD group and the standard-care group (Table 5). Total defined daily doses were
$11.9 \%$ and $10.1 \%$ lower with SDD and SOD, respectively, than with standard care.

\section{ADVERSE EVENTS}

In one patient receiving SDD, esophageal obstruction developed as a result of clotted oropharyngeal medication, which was removed through endoscopy. ${ }^{24}$

\section{I S C USS ION}

These data show an absolute reduction in mortality of 3.5 and 2.9 percentage points (corresponding to relative reductions of $13 \%$ and $11 \%$ ) at day 28 with SDD and SOD, respectively, among patients admitted to Dutch ICUs. Patients were treated with topical components at a cost per day of $\$ 1$ for SOD and $\$ 12$ for SDD, without evidence of the emergence of antibiotic-resistant pathogens or increased rates of detection of $C$. difficile toxin (at least during the relatively short period of study). This benefit was discernible only after adjustment for covariates. The overall study period was not long enough to evaluate the effect of the prophylactic regimens on microbial flora.

The strengths of the study include its pragmatic, multicenter, crossover design and the monitoring of inclusion rates. Overall, an estimated $89 \%$ of eligible patients were included. Cluster randomization was needed to avoid the possibility that one study regimen would influence the outcome of another regimen. A consequence of this study design is the absence of concealment of randomization. Although randomized treatment

\begin{tabular}{|c|c|c|c|c|c|}
\hline \multicolumn{6}{|l|}{ Table 5. Antibiotic Use.* } \\
\hline \multirow[t]{2}{*}{ Antibiotic } & \multicolumn{2}{|c|}{ SDD } & \multicolumn{2}{|c|}{ SOD } & \multirow{2}{*}{$\begin{array}{l}\text { Standard Care } \\
\text { No. of Defined } \\
\text { Daily Doses }\end{array}$} \\
\hline & $\begin{array}{l}\text { No. of Defined } \\
\text { Daily Doses }\end{array}$ & $\begin{array}{l}\text { Percent Change } \\
\text { (vs. Standard Care) }\end{array}$ & $\begin{array}{l}\text { No. of Defined } \\
\text { Daily Doses }\end{array}$ & $\begin{array}{l}\text { Percent Change } \\
\text { (vs. Standard Care) }\end{array}$ & \\
\hline Penicillins & 9,767 & -27.8 & 12,805 & -5.3 & 13,523 \\
\hline Carbapenems & 724 & -45.7 & 995 & -25.4 & 1,334 \\
\hline Cephalosporins & 8,473 & +86.6 & 3,935 & -13.3 & 4,541 \\
\hline Quinolones & 2,637 & -31.4 & 3,291 & -14.4 & 3,846 \\
\hline Lincosamides & 473 & -11.6 & 553 & +3.4 & 535 \\
\hline Other antibiotics & 7,589 & -23.4 & 8,720 & -12.0 & 9,909 \\
\hline All systemic antibiotics & 29,663 & -11.9 & 30,299 & -10.1 & 33,688 \\
\hline
\end{tabular}

* SDD denotes selective digestive tract decontamination, and SOD selective oropharyngeal decontamination. 
assignments for study periods were concealed, the actual inclusion of patients was not randomized, and the physicians responsible for patient inclusion were aware of the assigned intervention. Blinding of physicians (or having a third person, who was unaware of the assigned interventions, overseeing inclusion) was deemed impossible. To minimize the risk of selection bias due to differences in patient inclusion among study centers and during different study periods, inclusion rates were monitored frequently for any instances of selective inclusion. Nevertheless, despite the use of objective inclusion criteria and the provision of continual feedback on inclusion rates to the participating centers, baseline differences were present between the standard-care group and both intervention groups, with patients in the intervention groups tending to be older, more likely to be intubated, and less likely to be surgical patients and tending to have a higher baseline APACHE II score. These differences were not consistent with chance, and they account for the differences between the crude and adjusted outcomes (Table 2).

The microbiologic aims of treatment with SDD or SOD were achieved in this study. During the SDD periods, all patients received intravenous prophylaxis with cefotaxime, and the desired microbiologic effects on carriage of gram-negative bacteria in the respiratory and intestinal tracts were achieved. Rates of eradication of gram-negative bacteria in the intestines and oropharynx were slightly higher than those reported by Stoutenbeek et al. ${ }^{7}$ and others. ${ }^{25,26}$ During the SDD and SOD study periods, prevalence rates for antibioticresistant gram-negative bacteria were lower than they were during the standard-care periods. These results are consistent with the finding, reported by de Jonge et al. ${ }^{2}$ and others, ${ }^{27,28}$ that in settings with low levels of circulating antibiotic-resistant organisms, SDD is not associated with increased selection or induction of antibiotic resistance in the short term. However, in settings with high levels of endemic, multidrug-resistant gram-negative bacteria ${ }^{17,29}$ or methicillin-resistant S. aureus, ${ }^{18}$ SDD was associated with increased selection of such pathogens.

A limitation of our study is that the original analysis plan was not appropriate for the study design. Although analyses similar to that origi- nally proposed have been widely used to assess data from cluster-randomization trials, they increase the chance of incorrect inferences. Conclusions based on such analyses cannot be considered reliable. ${ }^{21,22}$ Faced with the choice between performing an analysis known to be inappropriate and creating a new analysis plan, we decided that the latter was preferable. Very similar conclusions about the interventions would have been reached had the primary outcome been inhospital mortality, as originally planned (with SDD very slightly less effective than SOD), after adjustment for baseline imbalances (Table 2). Evidence for the effectiveness of the interventions is supported by the significant reductions in the incidence of ICU-acquired bacteremia for important nosocomial pathogens in both intervention groups. Of note, the multiple comparisons of standard care with SDD and SOD increase the likelihood of type I errors.

Our finding that SDD and SOD have similar effects on survival raises questions about the relevance of systemic therapy with cefotaxime during the first 4 days of gastric and intestinal decontamination. Considering the importance of antibiotic resistance in ICUs, the SOD regimen seems preferable to the SDD regimen because it does not include widespread systemic prophylaxis with cephalosporins and involves a lower volume of topical antibiotics, thus minimizing the risk of selection for and development of antibiotic resistance in the long term. Furthermore, oropharyngeal decontamination with antiseptic agents, such as chlorhexidine, might be an alternative in environments with high levels of antibiotic resistance. $13,30,31$

Dr. Bonten reports receiving advisory-board fees from Ipsat Therapies, $3 \mathrm{M}$, and Novartis; consulting fees from Novartis, $3 \mathrm{M}$, and Bayer; and lecture fees from Cepheid and Pfizer. Dr. Kluytmans reports receiving consulting fees from $3 \mathrm{M}$, NovaBay, and Wyeth and lecture fees from $3 \mathrm{M}$ and Becton Dickinson. Dr. Cooper reports receiving a lecture fee from Novartis. Dr. Voss reports receiving grants from $3 \mathrm{M}$ and Medica. No other potential conflict of interest relevant to this article was reported.

We thank the nursing and medical staff of the participating ICUs, the hospital pharmacists and medical microbiologists at the participating hospitals, the hospital pharmacists of ZNB of Leeuwarden for preparation of study medications, research nurses Fieke Kloosterman and Ilja te Paske for quality surveys, and Diederick Grobbee, Arno Hoes, Ale Algra, Martin Bootsma, and Jan Vandenbroucke for analytical advice. The study is dedicated to Hilly de Vries-Hospers, M.D., Ph.D., medical microbiologist at the UMC Groningen, who died in 2005. 


\section{APPENDIX}

The authors' affiliations are as follows: the Division of Perioperative and Emergency Care (A.M.G.A.S., E.S.T.G., M.E.P., C.J.K.), the Division of Intensive Care Medicine (J.C.A.J.), the Department of Medical Microbiology (M.A.L-H., H.E.M.B., M.J.M.B.), the Department of Clinical Pharmacy (E.V.U.), and the Julius Center for Health Sciences and Primary Care (M.J.M.B.), University Medical Center, Utrecht; the Laboratory for Microbiology and Infection Control (J.A.J.W.K., D.B.-H.) and the Department of Anesthesiology and Intensive Care (N.J.M.M.), Amphia Hospital, Breda; the Laboratory for Medical Microbiology and Immunology (E.M.M.) and the Department of Intensive Care (K.K., F.H.B.), Rijnstate Hospital, Arnhem; the Department of Medical Microbiology (R.F.J.B., J.P.A.), the Departments of Internal Medicine and Pulmonary Diseases and Tuberculosis (T.S.W.), and the Department of Anesthesiology (L.P.H.J.A.), University Medical Center, Groningen; the Department of Intensive Care (J.G.H., P.P.) and the Department of Medical Microbiology (P.D.J.S., A.V.), Radboud University, Nijmegen Medical Center, Nijmegen; the Department of Medical Microbiology (A.T.B., E.J.K.) and the Department of Intensive Care (H.I.J.H.), Leiden University Medical Center, Leiden; the Department of Intensive Care (A.J.G.H.B.) and the Laboratory for Medical Microbiology (A.R.J.), Laboratories for Pathology and Medical Microbiology, Catharina Hospital, Eindhoven; the Department of Anesthesiology and Intensive Care (R.M.J.W.) and the Department of Medical Microbiology and Immunology (B.M.J.), St. Antonius Hospital, Nieuwegein; the Department of Intensive Care (P.J.W.D.) and the Department of Medical Microbiology (G.J.A.), Medical Center Haaglanden, The Hague; the Department of Intensive Care (L.F.V.) and the Regional Laboratory for Medical Microbiology and Infectious Diseases, Dordrecht-Gorinchem (I.H.M.E.F.); Albert Schweitzer Hospital, Dordrecht; the Department of Intensive Care (M.I.) and the Department of Medical Microbiology (S.F.T.T.), Diakonessen Hospital, Utrecht; the Intensive Care Department (G.H.K.) and the Department of Clinical Microbiology (W.P.), Slotervaart Hospital, Amsterdam; and the Department of Intensive Care (J.W.V.) and the Department of Medical Microbiology and Immunology (J.A.K.), Mesos Medical Center, Utrecht - all in the Netherlands; and the Centre for Infections Health Protection Agency Statistics, Modelling and Bioinformatics Department, London (B.S.C.).

\section{REFERENCES}

1. Vincent J-L. Nosocomial infections in adult intensive-care units. Lancet 2003; 361:2068-77.

2. de Jonge E, Schultz M, Spanjaard L, et al. Effects of selective decontamination of the digestive tract on mortality and acquisition of resistant bacteria in intensive care: a randomised controlled trial. Lancet 2003;362:1011-6.

3. D'Amico R, Pifferi S, Leonetti C, Torri V, Tinazzi A, Liberati A. Effectiveness of antibiotic prophylaxis in critically ill adult patients: systemic review of randomised controlled trials. BMJ 1998;316:1275-85.

4. Pugin J, Auckenthaler R, Lew DP, Suter PM. Oropharyngeal decontamination decreases incidence of ventilator-associated pneumonia: a randomized, placebocontrolled, double-blind clinical trial. JAMA 1991;265:2704-10.

5. Bergmans DC, Bonten MJ, Gaillard $\mathrm{CA}$, et al. Prevention of ventilator-associated pneumonia by oral decontamination: a prospective, randomized, double-blind, placebo-controlled study. Am J Respir Crit Care Med 2001;164:382-8.

6. van der Waaij D, Berghuis-de Vries JM, Lekkerkerk-van der Wees JEC. Colonization resistance of the digestive tract in conventional and antibiotic-treated mice. J Hyg (Lond) 1971;69:405-11.

7. Stoutenbeek CP, van Saene HKF, Miranda DR, Zandstra DF. The effect of selective decontamination of the digestive tract on colonization and infection rate in multiple trauma patients. Intensive Care Med 1984;10:185-92.

8. Nathens AB, Marshall JC. Selective decontamination of the digestive tract in surgical patients: a systematic review of the evidence. Arch Surg 1999;134:170-6.

9. Krueger WA, Lenhart FP, Neeser G, et al. Influence of combined intravenous and topical antibiotic prophylaxis on the incidence of infections, organ dysfunc- tions, and mortality in critically ill surgical patients: a prospective, stratified, randomized, double-blind, placebo-controlled clinical trial. Am J Respir Crit Care Med 2002;166:1029-37.

10. de la Cal MA, Cerdá E, García-Hierro $\mathrm{P}$, et al. Survival benefit in critically ill burned patients receiving selective decontamination of the digestive tract: a randomized, placebo-controlled, double-blind trial. Ann Surg 2005;241:424-30.

11. Bonten MJM, Gaillard CA, van Tie FH, Smeets HGW, van der Geest S, Stobberingh EE. The stomach is not a source for colonization of the upper respiratory tract and pneumonia in ICU patients. Chest 1994;105:878-84.

12. Garrouste-Orgeas M, Chevret S, Arlet $\mathrm{G}$, et al. Oropharyngeal or gastric colonization and nosocomial pneumonia in adult intensive care unit patients: a prospective study based on genomic DNA analysis. Am J Respir Crit Care Med 1997 156:1647-55.

13. Chan EY, Ruest A, Meade MO, Cook DJ. Oral decontamination for prevention of pneumonia in mechanically ventilated adults: systematic review and meta-analysis. BMJ 2007;334:889-900.

14. Bonten MJ, Kollef MH, Hall JB. Risk factors for ventilator-associated pneumonia: from epidemiology to patient management. Clin Infect Dis 2004;38:1141-9. 15. Bonten MJ, Kluytmans J, de Smet AM, Bootsma M, Hoes A. Selective decontamination of digestive tract in intensive care. Lancet 2003;362:2118-9.

16. van Nieuwenhoven CA, Buskens E, van Tiel FH, Bonten MJ. Relationship between methodological trial quality and the effects of selective digestive decontamination on pneumonia and mortality in critically ill patients. JAMA 2001;286: 335-40.

17. Verwaest C, Verhaegen J, Ferdinande
$\mathrm{P}$, et al. Randomized, controlled trial of selective digestive decontamination in 600 mechanically ventilated patients in a multidisciplinary intensive care unit. Crit Care Med 1997;25:63-71.

18. Lingnau W, Berger J, Javorsky F, Fille $\mathrm{M}$, Allerberger $\mathrm{F}$, Benzer $\mathrm{H}$. Changing bacterial ecology during a five-year period of selective intestinal decontamination. J Hosp Infect 1998;39:195-206.

19. Guidelines for the management of adults with hospital-acquired, ventilatorassociated, and healthcare-associated pneumonia. Am J Respir Crit Care Med 2005;171:388-416.

20. Tablan OC, Anderson LJ, Besser R, Bridges C, Hajjeh R. Guidelines for preventing health-care-associated pneumonia, 2003. Atlanta: Centers for Disease Control and Prevention, 2003. (Accessed December 5, 2008, at http://www.cdc.gov/ ncidod/dhqp/pdf/guidelines/CDCpneumo_ guidelines.pdf.)

21. Puffer S, Torgerson D, Watson J. Evidence for risk of bias in cluster randomised trials: review of recent trials published in three general medical journals. BMJ 2003;327:785-9.

22. Campbell MK, Elbourne DR, Altman DG. CONSORT statement: extension to cluster randomised trials. BMJ 2004;328: 702-8.

23. Branson RD, Davis K Jr, Campbell RS, Johnson DJ, Porembka DT. Humidification in the intensive care unit: prospective study of a new protocol utilizing heated humidification and hygroscopic condenser humidifier. Chest 1993;104:1800-5.

24. Smit MJ, van der Spoel JI, de Smet AM, de Jonge E, Kuiper RA, van Lieshout EJ. Accumulation of oral antibiotics as an adverse effect of selective decontamination of the digestive tract: a series of three cases. Intensive Care Med 2007;33: 2025-6. 
25. Kerver AJH, Rommes JH, MevissenVerhage EAE, et al. Prevention of colonization and infection in critically ill patients: a prospective randomized study. Crit Care Med 1988;16:1087-93.

26. Hartenauer U, Thülig B, Diemer W, et al. Effect of selective flora suppression on colonization, infection, and mortality in critically ill patients: a one-year, prospective consecutive study. Crit Care Med 1991; 19:463-73.

27. Stoutenbeek CP, van Saene HK, Little RA, Whitehead A. The effect of selective decontamination of the digestive tract on mortality in multiple trauma patients: a multicenter randomized controlled trial. Intensive Care Med 2007;33:261-70.

28. Heininger A, Meyer E, Schwab F, Marschal M, Unertl K, Krueger WA. Effects of long-term routine use of selective digestive decontamination on antimicrobial resistance. Intensive Care Med 2006; 32:1569-76.

29. Hammond JMJ, Potgieter PD, Saunders GL, Forder AA. Double-blind study of selective decontamination of the digestive tract in intensive care. Lancet 1992;340: 5-9.
30. Koeman M, van der Ven AJ, Hak E, et al. Oral decontamination with chlorhexidine reduces the incidence of ventilatorassociated pneumonia. Am J Respir Crit Care Med 2006;173:1348-55.

31. Segers P, Speekenbrink RG, Ubbink DT, van Ogtrop ML, de Mol BA. Prevention of nosocomial infection in cardiac surgery by decontamination of the nasopharynx and oropharynx with chlorhexidine gluconate: a randomized controlled trial. JAMA 2006;296:2460-6.

Copyright (c) 2009 Massachusetts Medical Society. 